\title{
Study of the Selectivity of Insulin-Like Growth Factor-1 Receptor (IGF1R) Inhibitors
}

\author{
Patrick Chène ${ }^{1, *}$, Jean-Christophe Hau ${ }^{1}$, Anke Blechschmidt ${ }^{2}$, Patricia Fontana ${ }^{1}$, Jacqueline Bohn ${ }^{1}$, \\ Catherine Zimmermann ${ }^{1}$, Alain De Pover ${ }^{1}$ and Dirk Erdmann ${ }^{1}$ \\ ${ }^{I}$ Druggability-Enzymology-Profiling unit, Disease Area Oncology, Novartis Institutes of BioMedical Research, Basel, \\ Switzerland \\ ${ }^{2}$ Center for Proteomic Chemistry, Novartis, Basel, Switzerland
}

\begin{abstract}
The insulin-like growth factor-1 receptor (IGF1R) is a drug target for oncology, and many studies are ongoing to identify compounds that inhibit its tyrosine kinase activity. IGF1R is highly homologous to the insulin receptor (IR) and IGF1R inhibition might be beneficial for patients, while IR inhibition may lead to limiting toxicity. Therefore selectivity for IGF1R over IR is the aim for drug design in this context. A few compounds that selectively inhibit IGF1R over IR in cells have been identified, but none of them show the same levels of selectivity in enzymatic assays. To determine whether this discrepancy is linked to the conditions used in the enzymatic assays, we have studied the interaction between known IGF1R inhibitors (NVP-AEW541, OSI906, AG538, NVP-TAE226) and phosphorylated/unphosphorylated IGF1R/IR proteins with both biophysical (isothermal calorimetry and surface plasmon resonance) and enzymatic methods. In this report, we describe the results of this study and comment on the different degrees of selectivity IGF1R versus IR measured in biochemical and cellular assays. Finally, our study provides new information on the biochemical and mechanism of action of these small molecular weight IGF1R inhibitors.
\end{abstract}

Keywords: Protein kinase, insulin-like growth factor-1 receptor, kinase inhibitor, surface Plasmon Resonance.

\section{INTRODUCTION}

The insulin-like growth factor-1 receptor is a receptor tyrosine kinase. It is a tetrameric protein formed of two $\alpha$ subunits and two $\beta$ subunits. The $\alpha$ subunits are entirely extracellular and house the ligand binding site. The $\beta$ subunits are formed of an extracellular domain containing cysteines that make disulfide bridges with the $\alpha$ subunits, a transmembrane region and a cytoplasmic domain. The latter can be further divided into a juxtamembrane domain, a kinase domain and a C-terminal domain [1]. The binding of the IGF1R ligands IGF1 and IGF2 to the $\alpha$ subunits induces a conformational change that leads to activation of the receptor and as a consequence to autophosphorylation of the $\beta$ subunits. Various proteins are then recruited to the phosphorylation sites activating different signal transduction cascades, such as the phosphatidylinositol-3-kinase and mitogen-activated protein pathways, which induce cell proliferation and inhibition of apoptosis [2]. Disruption of the $I g f l r$ gene causes growth retardation and leads to perinatal lethality due to organ hypoplasia [3] revealing the importance of IGF1R for normal growth and development.

Several lines of evidence indicate that IGF1R is important in the development and progression of cancer. It has been found that IGF1R plays a role in the establishment and maintenance of cellular transformation, itself or its ligands

*Address correspondence to this author at the WKL125 442, Novartis, CH4002 Basel, Switzerland; Tel: +41616962050; Fax: +41616963835;

E-mail: patrick_chene@yahoo.com are often overexpressed in human tumors, its activation protects against apoptosis, favors invasion and metastasis [4, 5]. This makes IGF1R an attractive drug target for anticancer therapy [6,7], and many drug discovery efforts are ongoing to identify agents that selectively block the IGF1R pathway in tumor cells [4-10]. The identification of low molecular weight molecules that, upon binding to the kinase domain of IGF1R, inhibit its catalytic activity is one approach under investigation. However, this strategy is far from straightforward, because the IGF1R protein shows a high structural homology with the insulin receptor (IR) [1]. For example, all the residues in contact with ATP, as observed in the crystal structure of activated IR [11], are conserved in IGF1R. The design of highly selective IGF1R inhibitors is essential, since the inhibition of the IR pathway may induce unacceptable toxicities as a result of effects on glucose homeostasis.

Even if this task seems to be very challenging, low molecular weight inhibitors of IGF1R have been identified, and some of them show some level of selectivity against IR in cell-based assays. However, these molecules show little if any selectivity against IR in enzymatic assays and as a consequence, the enzymatic data are considered not to be relevant to the measurement of IGF1R versus IR selectivity (hereafter, selectivity is taken to mean the selectivity of the compounds for IGF1R versus IR). This discrepancy between biochemical and cellular assay formats is particularly challenging, because chemistry must then only rely on cellular assays to measure compound selectivity. 
IGF1R inhibitors have mainly been studied in enzymatic assays, however other biochemical methods could be used to study their properties and assess their selectivity. We therefore decided to apply isothermal calorimetry (ITC) and surface plasmon resonance (SPR) to study the binding properties of well-known IGF1R inhibitors and to compare these results with enzymatic data. A small set of IGF1R inhibitors has been selected for this study (Fig. 1) on the basis of their different levels of selectivity. NVP-AEW541 (hereafter called AEW541) [12] is a nanomolar inhibitor of IGF1R both in enzymatic and cell-based assays. It does not show any selectivity in enzymatic assays, but shows a 27-fold selectivity in cell-based assays. AEW541 has demonstrated in vivo activity reducing the growth of IGF1R driven tumor xenografts [12]. OSI-906 (hereafter called OSI906) [13] is a nanomolar ATP inhibitor of IGF1R in enzymatic assays. This compound is also very potent in cell-based assays, and it shows an antitumor effect in vivo. OSI906 is not selective in enzymatic assays, but shows a 14-fold selectivity in cellbased assays [13]. This molecule is entering a phase III clinical trial in adrenocortical tumors. AG 538 (hereafter called AG538) is a nanomolar substrate (peptide) competitive inhibitor of IGF1R in enzymatic assays, which shows moderate activity in cell-based assays [14]. However, AG538 does not show any selectivity in enzymatic assays. NVP-TAE226 (hereafter called TAE226) [15] is a tyrosine kinase inhibitor active against IGF1R and IR both in vitro and in vivo. TAE226 is not selective in enzymatic assays. In addition to these molecules, which are selective IGF1R inhibitors, staurosporine (hereafter called STAURO) was also included in the study as a general non-selective kinase inhibitor.

In the following, we report the results of our study with these compounds by ITC, SPR and in enzymatic assays. The purpose of this work is the characterization of these compounds in biochemical assays.

\section{MATERIAL AND METHODS}

\section{Material}

AG538, STAURO and OSI906 can be purchased from Sigma-Aldrich and American Custom Chemical Corporations. AEW541 and TAE226were synthesized at the Novartis Institutes for BioMedical Research. Molecular weight markers were from BioRad.

\section{Cloning, Protein Expression and Purification}

The detailed description of the cloning, expression and purification of the different protein constructs utilized in this study will be described elsewhere [16]. Briefly, the cDNA encoding for the entire cytoplasmic domain of human IGF1R (aa 960-1367) and IR (aa 980-1382) was cloned into the pFastBacGST2-PreScission vector, and a His $_{6}$-tag was introduced at the C-terminus of the coding sequences. For Surface Plasmon Resonance experiments, a tag with a biotinylation recognition site (Avitag) was introduced between the PreScission cleavage site and the N-terminus of the protein. Proteins were expressed in Spodoptera frugiperda Sf9 cells. For the production of unphosphorylated and/or biotinylated proteins, vectors encoding for the phosphatase $\mathrm{YopH}$ and/or

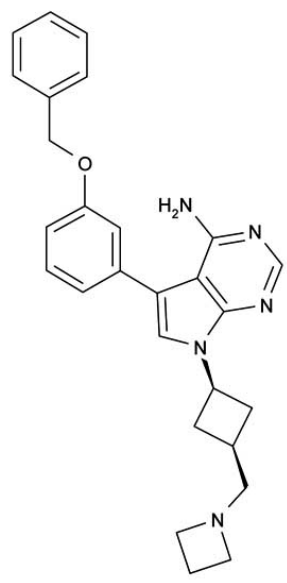

NVP-AEW541

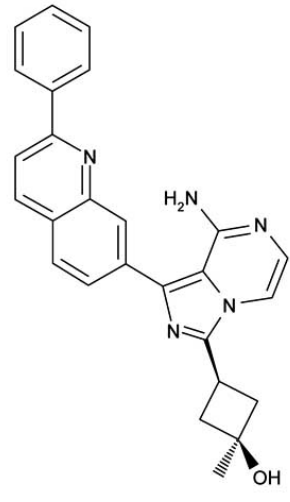

OSI-906

(PQIP)

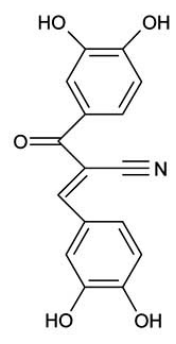

AG 538

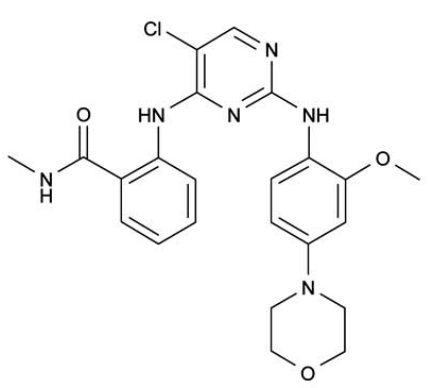

NVP-TAE226

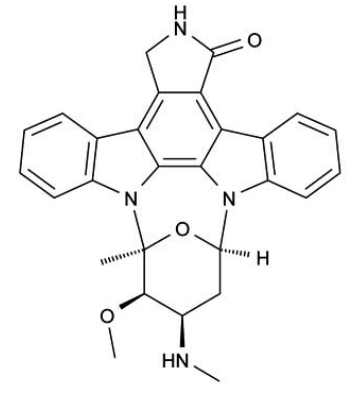

Staurosporine

Fig. (1). Chemical structure of the different compounds tested in this study. 
the biotin-protein ligase BirA were co-expressed with the IGF1R and IR vectors. The soluble proteins obtained from cell lysates were purified by two-step affinity chromatography purification (Glutathione sepharose 4B and His-Trap HP columns). The Glutathione S-transferase tag (GST) present at the N-terminus was removed with the PreScission protease (GE Healthcare) to generate the cleaved proteins. Protein concentrations were determined by the Bradford method, and the purity of the different protein preparations was determined by SDS-PAGE analysis and HPLC.

\section{High-Performance Liquid Chromatography-Tandem MS (HPLC-MS/MS)}

The proteins $(2 \mu \mathrm{M})$ were diluted in $50 \mathrm{mM}$ Hepes $\mathrm{pH}$ 7.2 (Gibco), $1 \mathrm{mM}$ DTT, $1 \mathrm{mM} \mathrm{MnCl}_{2}, 10 \mathrm{mM} \mathrm{MgCl}_{2}$ in the presence or absence of $5 \mathrm{mM}$ ATP. The reactions were run for $15 \mathrm{~min}$ at room temperature, stopped by the addition of an equal volume of $0.5 \mathrm{M}$ EDTA and kept on ice until LC-MS analysis. The proteins were separated on a HP1100 HPLC system (Hewlett Packard) equipped with a $1 \mathrm{~mm} x$ $150 \mathrm{~mm}$ column packed with POROS R1/H and kept at $80^{\circ} \mathrm{C}$ (PerSeptive Biosystems). The HPLC was controlled by MassLynx software (Waters, Manchester, UK). Proteins were eluted with a 12 min linear gradient 20 to $90 \%$ buffer B (water:acetonitrile $1: 9$ with $0.045 \%$ TFA) in buffer A $(0.05 \%$ TFA) (flow rate of $80 \mu \mathrm{l} / \mathrm{min}$ ). The eluted proteins were detected at $214 \mathrm{~nm}$. Mass spectrometry was carried out using a Q-ToF (Waters) quadrupole time-of-flight hybrid tandem mass spectrometer equipped with a Waters Z-type electrospray ionization source.

\section{Enzymatic Assays}

A radiometric assay was utilized to measure the protein kinase activity of the different proteins. All the reactions were carried out at room temperature $\left(23-25^{\circ} \mathrm{C}\right)$ in $96-w e l l$ $\mathrm{V}$-shaped plates (Brand). The same reaction buffer $(50 \mathrm{mM}$ Hepes $\mathrm{pH} 7.4,1 \mathrm{mM} \mathrm{MnCl}$, $10 \mathrm{mM} \mathrm{MgCl} 2,1 \mathrm{mM}$ DTT, $0.005 \%$ BSA, $0.01 \%$ Brij35) and peptidic substrate (AcEQEDEPEGDYFEWLE-NH ${ }_{2}$ ) were used for all the assays. All the compound stock solutions were prepared in DMSO.

Determination of the kinetic parameters. The GST. IGF1R and GST.IR $(1.3 \mu \mathrm{M})$ were incubated for $15 \mathrm{~min}$ in reaction buffer (without BSA) in the presence of $500 \mu \mathrm{M}$ ATP. The autophosphorylation reactions were diluted into reaction buffer, and the diluted enzymes $(0.2 \mathrm{nM})$ were incubated in the presence of different ATP/ ${ }^{33}$ PATP (0.6-20 $\mu \mathrm{M})$ and peptide $(2-30 \mu \mathrm{M})$ concentrations for $10 \mathrm{~min}$ at room temperature (steady state kinetic conditions). The reactions were stopped and processed as described below.

Assay with phosphorylated enzymes. The GST.IGF1R and GST.IR $(1.3 \mu \mathrm{M})$ proteins were incubated for $15 \mathrm{~min}$ in reaction buffer (without BSA) in the presence of $5 \mathrm{mM}$ ATP. The autophosphorylation reactions were diluted into reaction buffer containing the compounds and incubated for $30 \mathrm{~min}$. The peptide $(15 \mu \mathrm{M})$ and ${ }^{33} \gamma \mathrm{P}$-ATP $(0.003 \mu \mathrm{Ci} / \mu \mathrm{l})$ were added and the reactions were run for $10 \mathrm{~min}$ (final concentrations: $[\mathrm{ATP}]=6 \mu \mathrm{M}$; $($ Enzyme $]=1.6 \mathrm{nM}$; [DMSO] $=3 \%)$. The reactions were stopped and processed as described below. To determine the mode of inhibition of the compounds, these were incubated at different concentrations in the pres- ence of varying ATP concentrations $(0.6-20 \mu \mathrm{M})$ and a constant peptide concentration $(15 \mu \mathrm{M})$.

Assay with non-phosphorylated enzymes. The GST. IGF1R and GST.IR were incubated for $30 \mathrm{~min}$ in reaction buffer in the presence the compound. ATP $(45 \mu \mathrm{M})$ was added and autophosphorylation reactions were run for 15 $\min ([$ enzyme $]=3.3 \mathrm{nM})$. The peptide (final concentration $15 \mu \mathrm{M})$ and ${ }^{33} \gamma \mathrm{P}$-ATP $(0.005 \mu \mathrm{Ci} / \mu \mathrm{l})$ were added, and the reactions were run for $10 \mathrm{~min}$ (final concentrations: [ATP] = $30 \mu \mathrm{M}$, [enzymes] $=3.3 \mathrm{nM}$; [DMSO] $=3 \%$ ). The reactions were stopped and processed as described below.

All the enzymatic reactions were stopped by the addition of stop solution (200 $\mathrm{mM}$ phosphoric acid) and transferred onto pre-activated filter plates (96-well MultiScreen plates - Millipore). The plates were washed twice with $0.5 \%$ phosphoric acid and dried at room temperature. Microsint 40 (Perkin Elmer) was dispensed, and the bound radioactivity was counted in a TopCount NXT (Packard). To prevent filter saturation, the reaction solutions containing more than $15 \mu \mathrm{M}$ peptide were diluted into stop solution to reach a final peptide concentration of $15 \mu \mathrm{M}$ before loading to the membrane.

All the enzymatic data were analyzed by non-linear regression analysis as previously described [17].

\section{Isothermal Calorimetry}

IGF1R and IR proteins were extensively dialyzed at $4{ }^{\circ} \mathrm{C}$ against ITC buffer (50 mM Hepes $\mathrm{pH} 7.4,1 \mathrm{mM}$ TCEP, $0.01 \%$ Brij35). After dialysis the concentration of the protein was determined by HPLC and the proteins were diluted into ITC buffer (filtered at $0.22 \mu \mathrm{M}$ - Steriflip Millipore) to a final concentration of $80 \mu \mathrm{M}$ final. Compounds in solution in DMSO were diluted into filtered ITC buffer to a final concentration of $8 \mu \mathrm{M}(0.1 \%$ DMSO final). The protein, compound and buffer solutions were degassed under vacuum at room temperature. Experiments were conducted in a VP-ITC calorimeter (Microcal). The compound and protein solutions were placed in the cell and the titration syringe, respectively. All titrations were performed at $25^{\circ} \mathrm{C}$ with a stirring speed of $310 \mathrm{rpm}$, an injection volume of $10 \mu \mathrm{l}$ and a minimal $240 \mathrm{~s}$ duration between each injection. The baselines were manually drawn, and the data were zeroed assuming that the final injections represent the heat of dilution. The data were analyzed using the Microcal Origin software by fitting to a single-site binding model.

\section{Surface Plasmon Resonance}

All experiments were carried out using a Biacore T100 optical biosensor and Series S sensor Chip SA (Biacore AB). The chips were washed 3 times with $1 \mathrm{M} \mathrm{NaCl} / 50 \mathrm{mM}$ $\mathrm{NaOH}$, and the proteins $(0.2 \mathrm{mM})$ were injected for 40 or $300 \mathrm{~s}$ at a flow rate of $10 \mu \mathrm{l} / \mathrm{min}$ in immobilization buffer (100 mM PBS pH 7.5, 1 mM TCEP, 0.1\% Tween-20, 100 mM EDTA).

Phosphorylated enzymes were obtained by incubation of the unphosphorylated proteins $(2 \mu \mathrm{M})$ with $5 \mathrm{mM}$ ATP for $15 \mathrm{~min}$ at room temperature. Autophosphorylation reactions were stopped by the addition of EDTA (final concentration $100 \mathrm{mM})$. 
Kinetic experiments were performed at $25^{\circ} \mathrm{C}$ with a flow rate of $50 \mu \mathrm{l} / \mathrm{min}$ in running buffer $(50 \mathrm{mM}$ Hepes $\mathrm{pH} 7.5,1$ $\mathrm{mM}$ TCEP, 0.1\% Tween-20, 0.05\% BSA, 50 mM EDTA, $3 \%$ DMSO). The compounds were diluted in running buffer containing 3\% DMSO. An initial series of buffer blanks was injected to equilibrate the system and to correct for the excluded volume effect. DMSO correction series was performed from 2 to $4 \%$. Each cycle consisted of an injection phase of compounds (40 to $60 \mathrm{sec}$ ) and a dissociation phase of compounds (200 to $600 \mathrm{sec}$ ).

Data sets obtained with AEW541, TAE226 and STAURO were processed and analyzed using Scrubber 2 (Bio Logic Software). Double referencing association and dissociation phase data were globally fitted to a simple 1:1 interaction model or to a 1:1 interaction model that included a mass transport term $[18,19]$. OSI906 was tested using the "single cycle kinetic" method of the Biacore T100, which consists in the injection of 5 sample concentrations in the same cycle. The samples were injected in direct sequence, separated only by the time required to prepare the next injection. A dissociation period was included after the last injection. Similar experiments were also carried out with TAE226, which was used as a control to establish the method. "Single cycle kinetic" data were analyzed using the Biacore T100 evaluation software.

\section{RESULTS}

\section{Protein Constructs and Analytics}

The full-length cytoplasmic domains of IGF1R (residues 960-1367) and IR (residues 980-1382) were expressed as fusion proteins with a cleavable GST-tag at their N-terminus and a His-tag at their C-terminus. GST fusion proteins (GST.IGF1R and GST.IR) were used in the enzymatic assays, because the presence of a GST-tag favors autophosphorylation [20]. To avoid any interference during the ITC experiments, the GST-tag was removed to produce cleaved proteins (cIGF1R and cIR). For SPR experiments an Avitag was introduced at the N-terminus of the proteins (Avi.IGF1R and Avi.IR). This was specifically biotinylated by coexpression in vivo with the BirA biotin ligase, allowing immobilization (after cleavage of the GST-tag) of the purified proteins onto streptavidin-coated chips (Erdmann et al. submitted).

All the proteins were expressed in insect cells and purified to homogeneity by two-step affinity chromatography purification (Fig. 2A). Non-phosphorylated proteins were obtained by co-expression with the phosphatase $\mathrm{YopH}$, and the absence of phosphorylation was demonstrated by mass spectrometry (Fig. 2B). The phosphorylation and biotinylation status of Avi.IGF1R and Avi.IR was analyzed by mass spectrometry before (Fig. 2C) and after autophosphorylation (Fig. 2D). It should be noted that the phosphorylated Avitagged proteins are not single species (the same applies to the other phosphorylated enzymes used in this study) but a mixture of three forms of the proteins which are phosphorylated at 4,5 or 6 sites. These results are in agreement with previous results [20].

\section{Kinetic Characterization of the Proteins}

The steady-state kinetic parameters were determined in a radiometric assay. Since the IR protein follows a rapid- equilibrium random $\mathrm{Bi} \mathrm{Bi}$ mechanism [21, 22] and because IGF1R and IR are highly homologous proteins [2], the kinetic parameters were obtained by non-linear regression analysis using the rate equation corresponding to this mechanism [23]. The measured kinetic parameters of the IGF1R and IR proteins are similar (Table 1). There is also no major difference between the kinetic parameters of the GST tagged and the corresponding untagged proteins, which suggests that the GST has no influence on catalytic activity once the proteins are autophosphorylated.

\section{Determination of the Potency of the Compounds in the Biochemical Assays}

The potency of the selected inhibitors was measured in 2 different enzymatic assays. In the first one, the proteins were autophosphorylated in the presence of ATP and then incubated with the compounds. The peptidic substrate and radio labeled ATP were added and, after incubation, the amount of phosphorylated peptide was measured. This assay measures the inhibition of phosphorylated IGF1R/IR. In the second assay, the unphosphorylated enzymes were first incubated with the compounds, and then autophosphorylated with ATP. The peptidic substrate and radio labeled ATP were added and, after incubation, the amount of phosphorylated peptide was measured. This assay was used to estimate the ability of the compounds to inhibit unphosphorylated IGF1R/IR. Under such conditions the measured $\mathrm{IC}_{50}$ s have to be interpreted with caution since different enzymatic forms (phosphorylated and unphosphorylated) are present.

AEW541, TAE226, STAURO and OSI906 show good potency in the different assays (Table 2), and their $\mathrm{IC}_{50} \mathrm{~S}$ are similar in the assays with phosphorylated and unphosphorylated enzymes. In our experimental conditions, AEW541 shows a weak but reproducible IGF1R versus IR selectivity ( $\sim 5$-fold) in the assays with unphosphorylated proteins. AG538 gave a very weak inhibition in our assays. To investigate whether this low potency is linked to our experimental conditions, experiments were carried out removing BSA from the assay buffer. This had a dramatic effect on the potency of AG538. The $\mathrm{IC}_{50} \mathrm{~S}$ measured in the assay with phosphorylated proteins decreased from $121615 \mathrm{nM}$ or $92843 \mathrm{nM}$ in the presence of BSA to $110 \mathrm{nM}$ or $132 \mathrm{nM}$ in the absence of BSA for IGF1R or IR, respectively. Similar experiments carried out with AEW541 did not show such an effect: 45 $\mathrm{nM}$ or $110 \mathrm{nM}$ in the presence of BSA and $51 \mathrm{nM}$ or $121 \mathrm{nM}$ in the absence of BSA for IGF1R or IR, respectively. This excludes a general effect of BSA on the properties of the compounds in our assays. The Hill slopes measured with AG538 were also higher than the ones obtained with the other inhibitors $(\sim 3$ versus $\sim 1)$ and complete inhibition could not be obtained even at concentrations equal to 10 times $\mathrm{IC}_{50}$ (data not shown). To rule out the possibility that AG538 forms aggregates, a phenomenon sometimes observed with low molecular weight compounds [24], dynamic light scattering was utilized to detect the presence of aggregates. This compound did not formed detectable aggregates in the investigated experimental conditions (data not shown). Furthermore, mass spectrometry studies did not reveal the formation of covalent complexes between AG538 and IGF1R/IR (data not shown). However, because of its behavior in the enzymatic assays, AG538 was not further tested. 

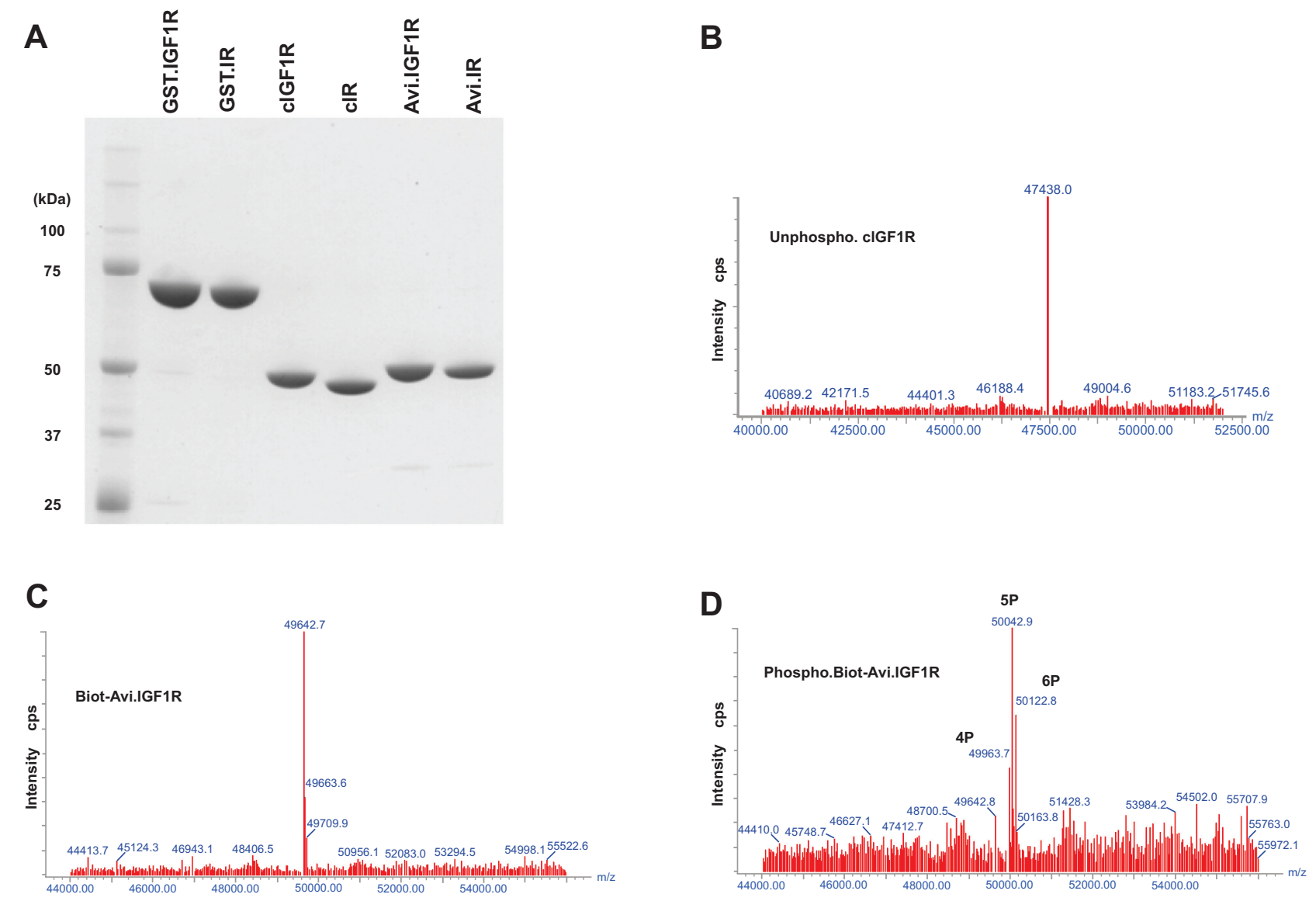

Fig. (2). Purity of the protein preparations. A. The different proteins $(2 \mu \mathrm{g})$ were analyzed by SDS-PAGE and the gels were stained with Gelcode blue stain reagent. The purity of unphosphorylated cIGF1R (B), biotinylated Avi.IGF1R (C) and biotinylated phosphorylated Avi.IGF1R (D) was also determined by HPLC-MS/MS as described under 'Materials and Methods'. Representative mass spectra are presented. The theoretical molecular weight $\left(\mathrm{MW}_{\text {th }}\right)$ of cIGF1R and biotinylated Avi.IGF1R are 47434 and 49641, respectively. The biotinylated phosphorylated Avi.IGF1R (D) is a mixture of proteins phosphorylated at $4\left(\mathrm{MW}_{\text {th }}=49961\right), 5\left(\mathrm{MW}_{\text {th }}=50041\right)$ and $6\left(\mathrm{MW}_{\text {th }}=50121\right)$ sites. Mass spectra for the corresponding IR proteins are provided in Supplementary Information (Fig. S1).

Table 1. Kinetic Parameters of the Enzymes. Initial Rates, Measured at Steady State, Were Fitted to a Rapid Equilibrium Binding Random Bi Bi Mechanism

\begin{tabular}{|l|c|c|c|c|}
\hline \multicolumn{1}{|c|}{ Proteins } & $\boldsymbol{\alpha}$ & $\mathbf{K}_{\text {ATP }}(\boldsymbol{\mu M})$ & $\mathbf{K}_{\mathbf{P}}(\boldsymbol{\mu M})$ & $\mathbf{V}_{\max }(\mu \mathrm{mole} / \mathbf{m i n} / \mathbf{m g})$ \\
\hline \hline GST.IGF1R & $0.5 \pm 0.2$ & $8 \pm 2$ & $18 \pm 4$ & $2.1 \pm 0.6$ \\
\hline cIGF1R & $0.8 \pm 0.1$ & $6 \pm 1$ & $9 \pm 2$ & $3 \pm 1$ \\
\hline GST.IR & $0.5 \pm 0.1$ & $9.5 \pm 0.1$ & $16 \pm 2$ & $1.1 \pm 0.3$ \\
\hline cIR & $0.8 \pm 0.1$ & $6.8 \pm 0.1$ & $15.4 \pm 0.5$ & $1.6 \pm 0.3$ \\
\hline
\end{tabular}

The values are the average of at least 2 independent measurements. $\alpha$ is the interaction factor between the two substrates.

Competition experiments between ATP and AEW541, TAE226, STAURO or OSI906 were carried out in the assay with phosphorylated IGF1R (Fig. 3). The three compounds AEW541, TAE226 and STAURO show clear competitive inhibition profiles. The $\mathrm{K}_{\mathrm{i}}$ values determined from these experiments are in agreement with the $\mathrm{K}_{\mathrm{i}}$ values that can be calculated from the $\mathrm{IC}_{50} \mathrm{~S}$ (Table 2). Competition experiments with OSI906 lead reproducibly to mixed inhibition profiles. However the main component in OSI906 inhibition is competitive because its $\mathrm{K}_{\mathrm{i}}$ (affinity constant for the free enzyme) is eight times lower than $\mathrm{K}_{\mathrm{i}}{ }^{\text {' (affinity constant for }}$ the enzyme substrate complex).

\section{Binding studies by Surface Plasmon Resonance}

The binding kinetics of the different compounds were studied by Surface Plasmon Resonance (SPR). These experiments were carried out either with unphosphorylated or 
Table 2. Potency of the Compounds in the Enzymatic Assays. The Potency of the Compounds was Determined in the Presence of the Phosphorylated (Phos-Enz) or of the Unphosphorylated (Unphos-Enz) Proteins

\begin{tabular}{|c|c|c|c|c|c|c|c|}
\hline \multirow[t]{2}{*}{ Compounds } & \multicolumn{2}{|c|}{$\mathrm{IC}_{50}(\mathrm{nM})$ IGF1R } & \multicolumn{2}{|c|}{$\mathrm{IC}_{50}(\mathrm{nM}) \mathrm{IR}$} & \multirow{2}{*}{$\begin{array}{c}\mathbf{K}_{\mathbf{i}} \\
(\mathbf{n M})\end{array}$} & \multirow[t]{2}{*}{$\mathbf{K}_{\mathbf{i}}^{\prime}(\mathbf{n M})$} & \multirow{2}{*}{$\begin{array}{c}\mathbf{K}_{\mathrm{i}} \mathbf{c a l c} \\
(\mathbf{n M})\end{array}$} \\
\hline & Phos-Enz & Unphos-Enz & Phos-Enz & Unphos-Enz & & & \\
\hline AEW541 & $45 \pm 4$ & $26 \pm 8$ & $110 \pm 28$ & $140 \pm 6$ & $14.4 \pm 0.4$ & - & 22 \\
\hline TAE226 & $8 \pm 2$ & $30 \pm 7$ & $5 \pm 2$ & $17 \pm 5$ & $2.8 \pm 0.7$ & - & 4 \\
\hline STAURO & $60 \pm 11$ & $147 \pm 27$ & $21 \pm 6$ & $72 \pm 6$ & $36 \pm 10$ & - & 30 \\
\hline OSI906 & $10 \pm 2$ & $5.5 \pm 0.3$ & $29 \pm 1$ & $16 \pm 1$ & $3 \pm 1$ & $24 \pm 7$ & n.d. \\
\hline AG538 & $121615 \pm 4248$ & $59387 \pm 7500$ & $92843 \pm 6891$ & $72064 \pm 5158$ & n. d. & & n.d. \\
\hline
\end{tabular}

The values are the average of at least 2 independent measurements. $n$. d.: not determined. $K_{i}$ represents the affinity of the substrate for the free enzyme. $K_{i}$ ' represents the affinity of the inhibitor for the enzyme substrate complex. $\mathrm{K}_{\mathrm{i}}$ values were determined with phosphorylated IGF1R from the experiments presented on Fig. (3). $\mathrm{K}_{\mathrm{i}}$ calc were calculated from the $\mathrm{IC}_{50}$ s measured with phosphorylated IGF1R using the formula: $\mathrm{IC}_{50}=\mathrm{K}_{\mathrm{i}} \mathrm{calc}\left(1+[\mathrm{S}] / \mathrm{K}_{\mathrm{m}(\mathrm{ATP})}\right.$. Since in our case $[\mathrm{S}]=\mathrm{K}_{\mathrm{m}(\mathrm{ATP})}, \mathrm{K}_{\mathrm{i}}$ calc=IC $\mathrm{I}_{50} / 2$. This calculation was only used for the ATP competitive inhibitors.
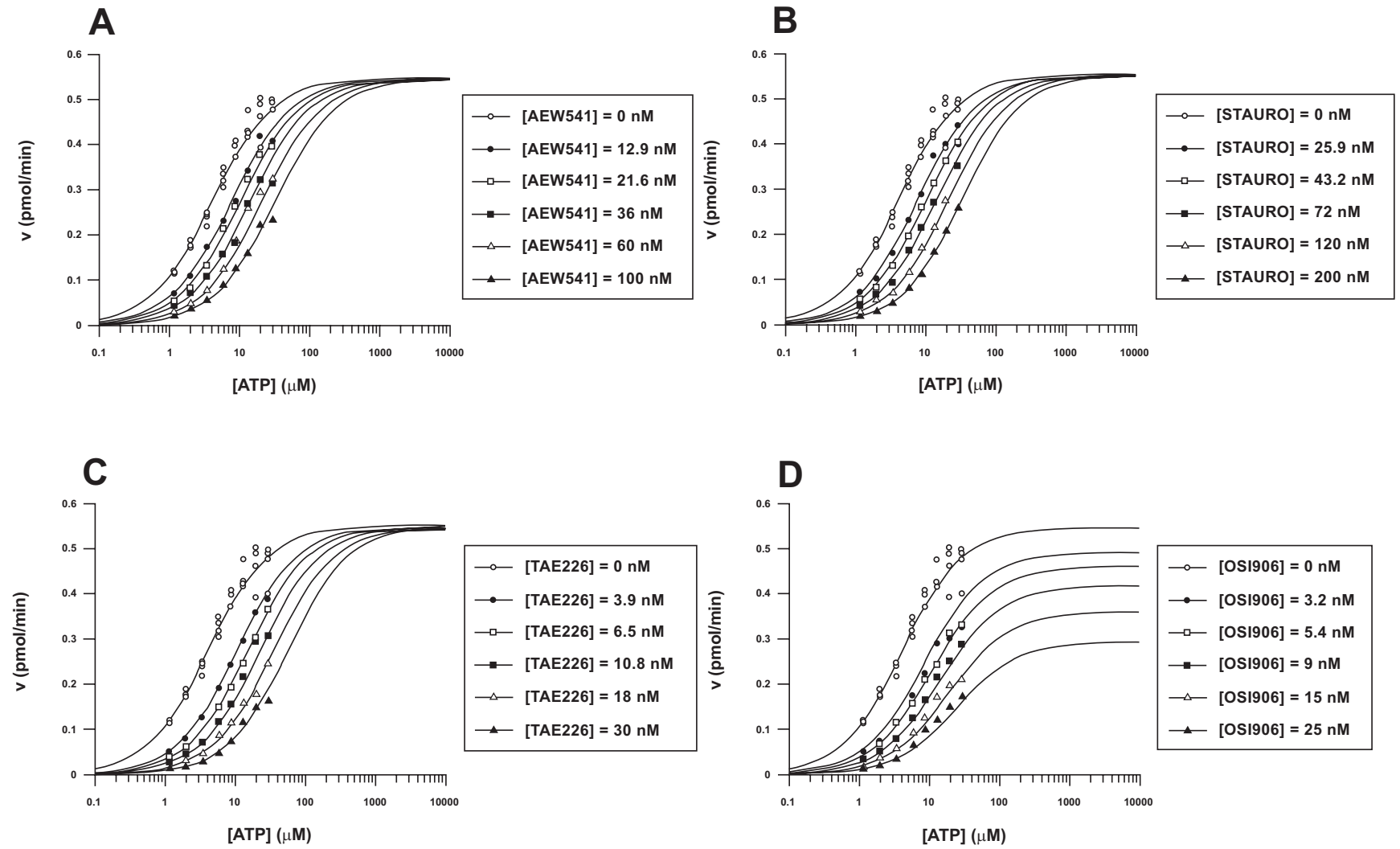

Fig. (3). Inhibition studies of phosphorylated IGF1R. Semi-logarithmic representation of the inhibition response curves of the protein by AEW541 (A), STAURO (B), TAE226 (C) and OSI906 (D) in the presence of a fixed peptide concentration and variable ATP concentrations. The response curves were globally fitted with different inhibition models, and the best one was chosen from a statistical analysis of the different fits [17].

phosphorylated biotinylated enzymes immobilized on streptavidin chips. Special care was taken with the phosphorylated proteins, because it has been shown that dephosphorylation occurs spontaneously when $\mathrm{Mg}^{2+}$ is present $[25,26]$. Therefore, after autophosphorylation and during immobilization, the enzymes were kept in the presence of excess EDTA to chelate $\mathrm{Mg}^{2+}$. Furthermore, control binding experiments with AEW541 were performed at different stages of each SPR experiment to assess whether the immobilized proteins had undergone excessive dephosphorylation.
Preliminary SPR experiments revealed that, once OSI906 is bound to the immobilized protein, it cannot be easily eliminated from the chips, suggesting that it has a low $\mathrm{k}_{\text {off }}$ (dissociation rate). It was therefore not possible to use the classical method to determine the kinetic parameters of OSI906. To avoid regeneration of the sensor surface, which could affect the properties of the proteins, we used the kinetic titration method [27]. To validate this methodology with IGF1R inhibitors, the kinetic parameters of TAE226 were determined by the kinetic titration method and com- 
pared to the parameters measured using the classical method. The $\mathrm{k}_{\text {on }}$ (association rate) and $\mathrm{k}_{\text {off }}$ for TAE226 obtained by kinetic titration with immobilized unphosphorylated IGF1R are $(3.7 \pm 0.6) \times 10^{5} \mathrm{M}^{-1} \mathrm{~s}^{-1}$ and $0.11 \pm 0.02 \mathrm{~s}^{-1}$, respectively. These values are in good agreement with those determined using the classical method (Table 3). Kinetic titration was therefore utilized to measure the kinetic parameters of OSI906.

The different kinetic parameters determined in this study are presented on Table $\mathbf{3}$ and a representative experiment is presented on Fig. (4). $\mathrm{K}_{\mathrm{d}}$ eq (dissociation constants derived from equilibrium data) of AEW541 and TAE226 were not determined with the phosphorylated enzymes, because equilibrium was not reached for all tested concentrations. $\mathrm{K}_{\mathrm{d}}{ }^{\text {eq }}$ was determined for the interaction between STAURO and the phosphorylated proteins and for all compounds with the unphosphorylated proteins. There is good agreement between $\mathrm{K}_{\mathrm{d}}{ }^{\text {eq }}$ and $\mathrm{K}_{\mathrm{d}}{ }^{\text {cin }}$ (the binding constant derived from kinetic data $-\mathrm{K}_{d}^{\text {cin }}=\mathrm{k}_{\text {off }} / \mathrm{k}_{\text {on }}$ ). However, there is a low correlation between the $\mathrm{IC}_{50} \mathrm{~s} / \mathrm{K}_{\mathrm{i}}$ obtained from the enzymatic assays (Table 2 ) and the $K_{d}$ measured by SPR (Table 3 ) with the phosphorylated enzymes. The presence of a biotinylated Avitag in the constructs used in SPR does not explain this discrepancy since, in enzymatic assays, the compounds have similar $\mathrm{IC}_{50} \mathrm{~S}$ with both the Avi-tagged and the GST-tagged proteins (data not shown).

All the compounds show a higher affinity for the phosphorylated enzymes. The $\mathrm{K}_{\mathrm{d}}{ }^{\mathrm{cin}} \mathrm{IR} / \mathrm{K}_{\mathrm{d}}{ }^{\mathrm{cin}} \mathrm{IGF} 1 \mathrm{R}$ ratios are 3.3, $0.8,0.4$ and 4.5 (unphosphorylated enzymes) and 2.9, 0.7, 0.4 and 2.5 (phosphorylated enzymes) for AEW541, TAE226, STAURO and OSI906, respectively. As observed in the enzymatic assays, the compounds show little if any selectivity in SPR, but the same trend is observed with the two methods. AEW541 and OSI906 have a slight preference for IGF1R and STAURO for IR.

The increased potency observed from STAURO to TAE226 to AEW541 correlates well, for most enzyme forms, with a decrease in $\mathrm{k}_{\text {off }}$ with little change in $\mathrm{k}_{\text {on }}$. More surpris- ing are the data obtained with OSI906, which is structurally related to AEW541 (Fig. 1). OSI906 has very different on and off-rates that could not be predicted on the basis of its difference in potency with AEW541. For example, OSI906 and AEW541 show only a 3.4-fold difference in $\mathrm{K}_{\mathrm{d}}^{\text {cin }}$ but a 918-fold difference in $\mathrm{k}_{\text {off }}$, with phosphorylated IGF1R. On the sole basis of this low $\mathrm{k}_{\text {off }}$ value, one would expect OSI906 to be far more potent, but this low off-rate is compensated by a reduced $k_{\text {on }}$ and its on-rate is 260 times lower than that measured for AEW541.

The off-rates of AEW541, TAE226 and STAURO are similar with the phosphorylated and unphosphorylated proteins, but their $\mathrm{k}_{\text {on }} \mathrm{s}$ are different for these two enzyme forms. The on-rates measured for the phosphorylated proteins appear to be higher than those for the unphosphorylated enzymes. To confirm this observation, we compared (MannWhitney rank sum tests; $\mathrm{n} \geq 4$ independent experiments) the $\mathrm{k}_{\mathrm{on}} \mathrm{s}$ obtained with the two enzymatic forms. This analysis shows that there is a statistical difference between $\mathrm{k}_{\text {on }} \mathrm{s}$ measured with phosphorylated and unphosphorylated IGF1R: $p=0.004,<0.001,0.002$ for AEW541, TAE226 and STAURO, respectively. Similar differences were obtained with IR: $p=0.001,<0.001,0.003$ for AEW541, TAE226 and STAURO, respectively. Therefore the on-rates for the phosphorylated proteins are faster than the ones for the unphosphorylated ones.

\section{Isothermal Calorimetry (ITC)}

The interaction between the compounds and the unphosphorylated proteins was also studied by isothermal calorimetry. The results of these experiments are summarized on Table 4 and a representative experiment is presented on Fig. (5). For all four compounds and both proteins a stoechiometry (n) of 1 was measured. The values of the thermodynamic parameters (enthalpy, $\Delta \mathrm{H}$ and entropy, $\Delta \mathrm{S}$ ) show that there is a large enthalpic contribution in the binding energy $(\Delta \mathrm{G})$ of AEW541, OSI906 and TAE226 while the binding of STAURO is mainly entropically driven. $\Delta \mathrm{H}$ and $\Delta \mathrm{S}$ values of TAE226, STAURO and OSI906 are similar for both pro-

Table 3. Kinetic Parameters for the Binding of the Different Inhibitors to Phosphorylated/Unphosphorylated IGF1R and IR

\begin{tabular}{|c|c|c|c|c|c|c|c|c|}
\hline \multirow[t]{2}{*}{ Compounds } & \multicolumn{4}{|c|}{ Unphosphorylated IGF1R } & \multicolumn{4}{|c|}{ Phosphorylated IGF1R } \\
\hline & $\mathbf{k}_{\text {on }}(M-1 s-1)$ & $\mathbf{k}_{\text {off }}(\mathbf{s}-1)$ & $\mathbf{K}_{d}^{\operatorname{cin}}(\mathbf{n M})$ & $\mathbf{K}_{d}^{\mathrm{eq}}(\mathbf{n M})$ & $k_{\text {on }}(M-1 s-1)$ & $\mathbf{k}_{\text {off }}(\mathrm{s}-1)$ & $\mathbf{K}_{d}^{\operatorname{cin}}(\mathbf{n M})$ & $\mathbf{K}_{\mathrm{d}}^{\mathrm{eq}}(\mathbf{n M})$ \\
\hline AEW541 & $(4.0 \pm 0.7) \times 105$ & $0.09 \pm 0.01$ & $212 \pm 20$ & $227 \pm 36$ & $(1.3 \pm 0.2) \times 107$ & $0.09 \pm 0.02$ & $6.8 \pm 0.9$ & n. d. \\
\hline TAE226 & $(6.1 \pm 0.8) \times 105$ & $0.16 \pm 0.02$ & $272 \pm 44$ & $300 \pm 44$ & $(2.0 \pm 0.4) \times 106$ & $0.04 \pm 0.01$ & $21 \pm 2$ & n. d. \\
\hline STAURO & $(4.1 \pm 0.6) \times 105$ & $0.8 \pm 0.1$ & $1990 \pm 127$ & $2136 \pm 131$ & $(2.1 \pm 0.3) \times 106$ & $0.38 \pm 0.05$ & $182 \pm 5$ & $216 \pm 20$ \\
\hline \multirow[t]{2}{*}{ OSI906 } & $(3.1 \pm 0.4) \times 104$ & $(4.0 \pm 0.7) \times 10-4$ & $13 \pm 4$ & n. a. & $(5 \pm 2) \times 104$ & $(9.8 \pm 0.4) \times 10-5$ & $2 \pm 1$ & n. a. \\
\hline & \multicolumn{4}{|c|}{ Unphosphorylated IR } & \multicolumn{4}{|c|}{ Phosphorylated IR } \\
\hline AEW541 & $(4.4 \pm 0.8) \times 105$ & $0.30 \pm 0.03$ & $707 \pm 143$ & $820 \pm 155$ & $(5 \pm 2) \times 106$ & $0.11 \pm 0.04$ & $20 \pm 3$ & n. d. \\
\hline TAE226 & $(5.7 \pm 0.6) \times 105$ & $0.13 \pm 0.01$ & $227 \pm 30$ & $300 \pm 23$ & $(1.9 \pm 0.3) \times 106$ & $0.03 \pm 0.01$ & $15 \pm 2$ & n. d. \\
\hline STAURO & $(5.6 \pm 0.8) \times 105$ & $0.38 \pm 0.06$ & $710 \pm 181$ & $711 \pm 183$ & $(2.7 \pm 0.5) \times 106$ & $0.19 \pm 0.07$ & $70 \pm 17$ & $70 \pm 2$ \\
\hline OSI906 & $(4.0 \pm 0.3) \times 104$ & $(2.4 \pm 0.4) \times 10-3$ & $59 \pm 15$ & n. a. & $(9 \pm 4) \times 104$ & $(4.3 \pm 0.2) \times 10-4$ & $5 \pm 2$ & n. a. \\
\hline
\end{tabular}

The kinetic parameters were determined at $25^{\circ} \mathrm{C}$ with a Biacore T100. The kinetic parameters of AEW541, TAE226 and STAURO were obtained assuming a simple $1: 1$ interaction model or a 1:1 interaction model that included a mass transport term using Scrubber 2. For OSI906, the kinetic parameters were determined by kinetic titration with the Biacore T100 evaluation software. Mean values \pm standard errors of the means are given. These data were generated from at least four independent experiments carried out with different immobilization levels and different protein batches. $n$. a.: not applicable. $n$. d.: not determined (see text for more explanations). $\mathrm{k}_{\text {on }}$ : rate of association; $\mathrm{k}_{\text {off }}$ : rate of dissociation; $\mathrm{K}_{\mathrm{d}}$ eq: dissociation constant derived from equilibrium data; $\mathrm{K}_{\mathrm{d}}{ }^{\text {cin }}$ : dissociation constant derived from kinetic data $\left(\mathrm{K}_{\mathrm{d}}{ }^{\text {cin }}=\mathrm{k}_{\mathrm{off}} / \mathrm{k}_{\mathrm{on}}\right)$. 
Table 4. Thermodynamic Parameters of the Interaction Between the Inhibitors and Unphosphorylated IGF1R and IR

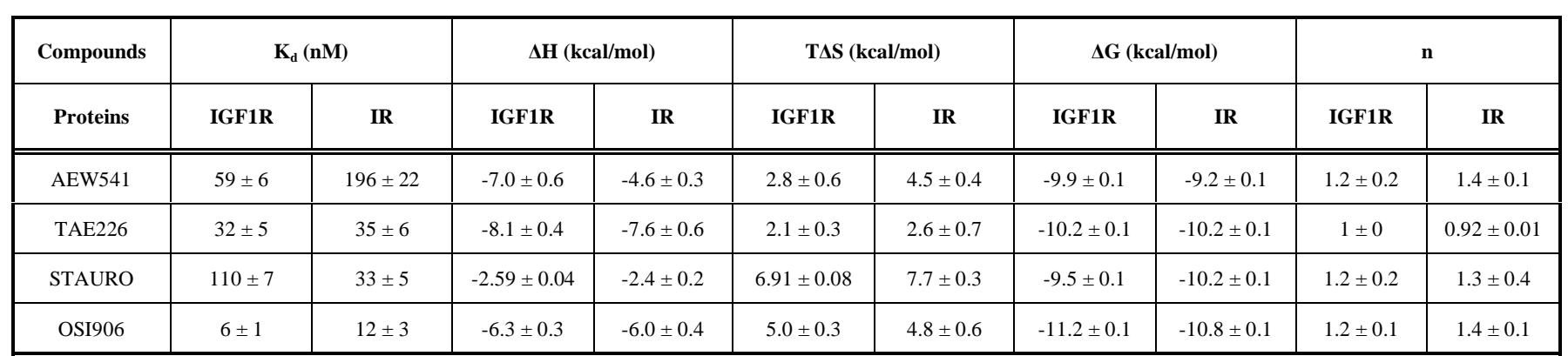

The Parameters were Obtained by Titration Experiments of Protein Solutions Into Inhibitor Solutions at $25^{\circ} \mathrm{C}$ With a VP-ITC Calorimeter (Microcal). The Binding Curves were Fitted Assuming a Simple 1:1 Interaction with the Microcal Origin Software. Mean Values \pm Standard Errors of the Means are Given. These Data Were Generated from at Least Two Independent Experiments Carried out with Different Protein Batches. $\mathrm{K}_{\mathrm{d}}$ : Dissociation Constant; $\Delta \mathrm{H}$ : Change in Enthalpy; $\Delta \mathrm{S}$ : Change in Entropy; $\Delta \mathrm{G}$ : Change in Free Energy of Binding Obtained from $\Delta \mathrm{G}=\Delta \mathrm{H}-\mathrm{T} \Delta \mathrm{S}$ ( $\mathrm{T}$ : Temperature); $\mathrm{n}=$ Number of Sites.
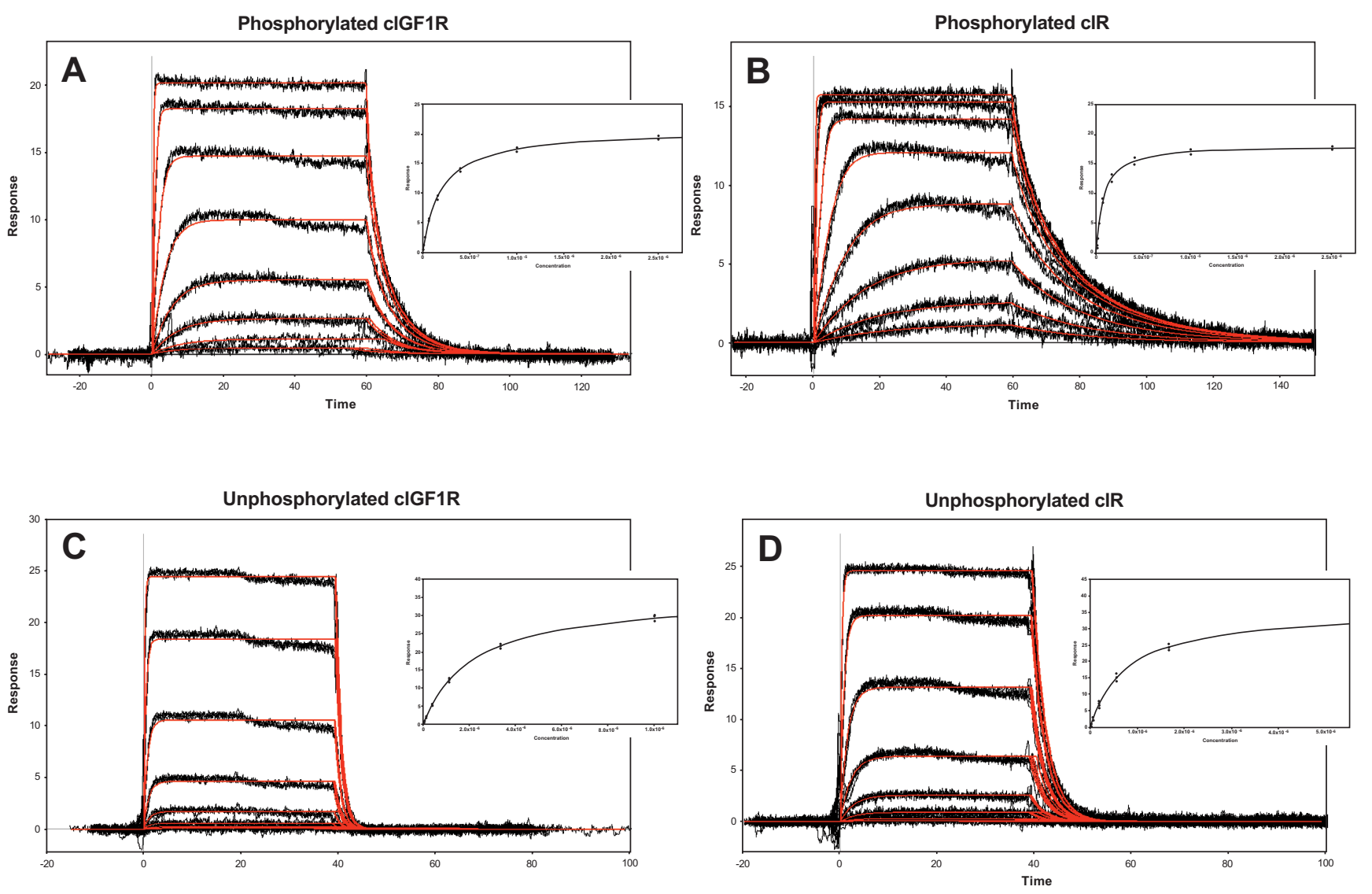

Fig. (4). Kinetic characterization of inhibitors binding to phosphorylated and unphosphorylated biotinylated Avi.IGF1R and Avi.IR proteins. The proteins were immobilized onto streptavidin-coated chips, and the binding kinetics of the compounds were carried out with a Biacore T100 optical sensor. Representative sensorgrams of the binding of STAURO to phosphorylated (A) and unphosphorylated (C) biotinylated Avi.IGF1R and to phosphorylated (B) and unphosphorylated (D) biotinylated Avi.IR are represented. Representative sensorgrams obtained with the other compounds are provided in Supplementary information (Fig. S2). The data were analyzed with a simple 1:1 interaction model or a 1:1 interaction model that included a mass transport term using Scrubber 2. The inserts represent the fitted plots of the responses measured at equilibrium $\left(\mathrm{R}_{\mathrm{eq}}\right)$ plotted against compound concentration.

teins, but, the relative enthalpy/entropy contribution to binding energy is modified between IGF1R and IR for AEW541. This effect is not observed with OSI906, which is structurally similar to AEW541. It is difficult to rationalize this finding without having tested more analogs of these compounds. The ratios $\mathrm{K}_{\mathrm{d}} \mathrm{IR} / \mathrm{K}_{\mathrm{d}} \mathrm{IGF} 1 \mathrm{R}$ are 3.3, $1.1,0.3$ and 2 for AEW541, TAE226, STAURO and OSI906, respectively.
This shows that a weak selectivity is measured with the unphosphorylated proteins by ITC. The correlation between the $\mathrm{K}_{\mathrm{d}}{ }^{\text {cin }}$ obtained by SPR and the $\mathrm{K}_{\mathrm{d}}$ measured by ITC is low. The $K_{d}$ of AEW541 measured by ITC with the biotinylated Avitag proteins do not differ more than twofold from the $\mathrm{K}_{\mathrm{d}}$ determined with the untagged proteins (data not shown). 

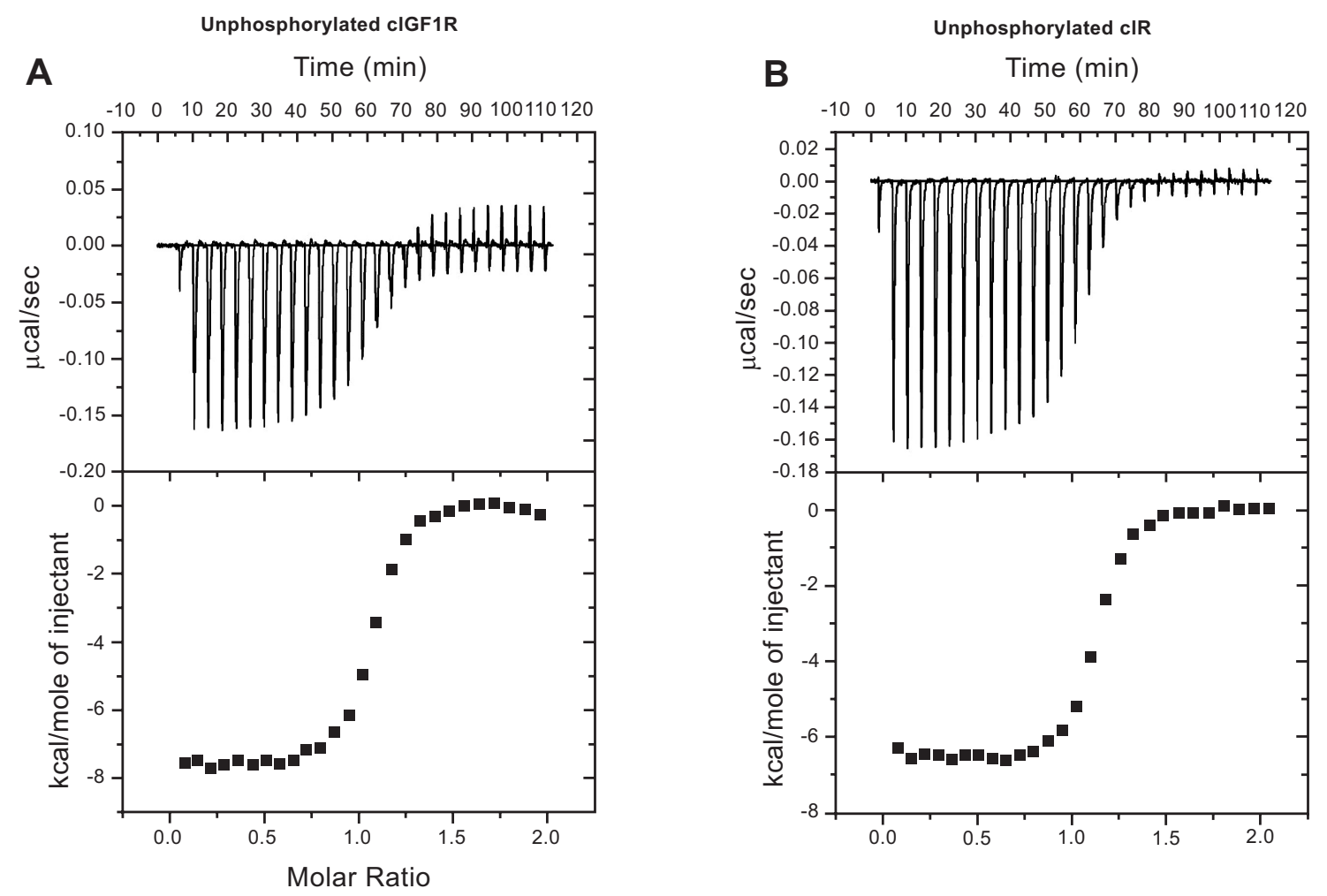

Fig. (5). Isothermal calorimetry analysis of the interaction between the compounds and the unphosphorylated proteins. The IGF1R (A) and IR (B) proteins were titrated into a solution of inhibitor as described under 'Material and Methods' in a VP-ITC calorimeter (Microcal). The upper part of the graphs shows raw data in terms of $\mu \mathrm{cal} / \mathrm{sec}$ plotted against time in minutes, after subtraction of the integration baseline. The lower part of the graph shows normalized integration data in terms of kcal/mole of protein plotted against molar ratio. The data represented on the figure correspond to the ITC measurements obtained with TAE226, the ITC measurements obtained with other compounds are provided in Supplementary Information (Fig. S3).

\section{DISCUSSION}

IGF1R is an attractive target for oncology, and many compounds that inhibit its tyrosine kinase activity have been identified. A real challenge for medicinal chemistry is to design molecules that selectively inhibit IGF1R, but not its close homolog the IR protein. Today IGF1R inhibitors with good selectivity in cellular assays have been identified. However, none of them shows this level of selectivity in enzymatic kinase assays, which suggests that the selectivity of IGF1R inhibitors cannot be measured using these methods. To determine whether biochemical assays other than enzymatic kinase assays allow the selectivity observed in cells to be measured, we have studied the interaction of five compounds - AEW541, TAE226, AG538, OSI906 and STAURO - with phosphorylated/unphosphorylated IGF1R/ IR using surface plasmon resonance and isothermal calorimetry.

Altogether, our data show that the selectivity measured in cells is not obtained in any of the assays that we have used or with any of the enzyme forms tested. We only observe a small trend for AEW541 and OSI906 to be more selective for IGF1R and for STAURO to be more selective for IR. These results clearly indicate that the lack of selectivity measured so far with IGF1R inhibitors in the enzymatic kinase assays is not due to these assays, since similar results are obtained using other biochemical methods, such as SPR or ITC. This tends to support the earlier statement: "cellular assays may be preferred over biochemical assays to meaningfully assess selectivity of a novel pharmacologic agent between closely related target enzymes" [13]. Obviously it can be hypothesized that the protein constructs used in biochemical assays only cover part of the conformational landscape taken by the full-length proteins in cells. In addition, the oligomerization status of the proteins may also influence the selectivity of the compounds. In cells, IGF1R and IR are covalent dimers, while at the low concentrations used in the biochemical assays they might be preferentially present as monomers even if tagged with GST, which favors dimerization. However, it is interesting to look in more detail at the published data for AEW541 and OSI906, two compounds selected in this study for their cellular selectivity. The $\mathrm{IC}_{50} \mathrm{~S}$ measured with AEW541/OSI906 are 150/24 and 86/19 nM for IGF1R inhibition in enzymatic and cellular assays, respectively $[12,13]$. For $\mathrm{IR}$ inhibition, the $\mathrm{IC}_{50} \mathrm{~S}$ are $140 / 31$ and 2300/261 nM. The cellular assays used in these studies, which score for inhibition of the ligand-induced phosphorylation of IGF1R/IR, provide a rather direct measure of the inhibition of these proteins in a cellular environment. Keeping in mind that comparison of $\mathrm{IC}_{50} \mathrm{~s}$ obtained from different assay formats might be misleading, we nevertheless observe that the $\mathrm{IC}_{50}$ s measured with AEW541 and OSI906 are similar in the enzymatic and cellular assays for IGF1R inhibition, but not for IR inhibition. Of course, the possibility cannot be excluded that, despite having a high primary sequence and structural homology and similar kinetic parameters (Table 
1), purified IGF1R might behave like its cellular counterpart, while IR does not. Alternatively, one could hypothesize that the biochemical assays correctly measure selectivity (and potency) but that, in cells, the inhibitors show a different selectivity because IGF1R and IR are regulated in a different manner. If the latter applies, it might be more difficult to rationalize the effects of compound modifications on their selectivity, since this would be independent of the precise interaction between these compounds and their targets. It is also conceivable that compounds targeting different conformations of IGF1R/IR behave in a different manner. For example, if unphosphorylated IGF1R and IR are regulated in the same way in cells, molecules binding to these enzymes may show the same selectivity in biochemical and cellular assays.

Our study also brings new information on the properties of some IGF1R inhibitors. We have found that AG538 is a weak inhibitor of IGF1R. This finding is similar to the one made by Li et al. [28] with purified IGF1R kinase domain, but is not in agreement with the data published by Blum et al. obtained with partially purified full-length IGF1R receptor [14]. The effect of AG538 may therefore dependent on the construct and/or the conditions utilized in the assay. In agreement with previous results [29], we find that in the enzymatic assays OSI906 inhibits both phosphorylated and unphosphorylated IGF1R with similar potency. However SPR shows that it has a higher affinity for phosphorylated IGF1R. This difference can be explained by the fact that during the course of the reaction in the enzymatic kinase assay with unphosphorylated IGF1R, this protein becomes phosphorylated and it phosphorylates the peptide substrate. Therefore the $\mathrm{IC}_{50}$ s obtained with this experimental set-up, in addition to the inhibition of the unphosphorylated enzyme, also reflect the inhibition of the phosphorylated enzyme. Compounds targeting phosphorylated IGF1R should then show similar $\mathrm{IC}_{50} \mathrm{~S}$ in this assay and in the assay with phosphorylated IGF1R. Wu et al. have measured the inhibition of IGF1R autophosphorylation by OSI906 [29]. Phosphorylated IGF1R is produced as well in this assay and it should be the most active species in the presence of $1 \mathrm{mM}$ ATP $\left(\mathrm{K}_{\mathrm{m}(\mathrm{ATP})}\right.$ phosphorylated IGF1R $\sim 100 \mu \mathrm{M} \mathrm{K}_{\mathrm{m} \text { (ATP) }}$ unphosphorylated IGF1R $\sim 700 \mu \mathrm{M}$ [25]) and it should phosphorylate the remaining unphosphorylated protein during the autophosphoryaltion process. Therefore this assay also scores for the inhibition of phosphorylated IGF1R, and the same conclusion can be drawn as with our assay. Altogether this shows that SPR is a very useful tool for studying the properties of kinase inhibitors in detail. This is further demonstrated when looking at the kinetic properties of OSI906 and AEW541. The differences in the on- and off-rates measured with these two molecules (Table 3 ) could not be predicted on the sole basis of their different potencies (Table 2). Using SPR, it can be shown that these closely related molecules have distinct binding kinetic mechanisms. It has been proposed that compounds with low $\mathrm{k}_{\text {off }}$ have potential advantages over molecules with fast off-rates (for example see [30]). OSI906, which dissociates about 900 times more slowly from phosphorylated IGF1R than AEW541, should thus be a better candidate than AEW541, but it also dissociates 55 times more slowly from IR than AEW541. Since the inhibition of IR may induce toxicity, this low off-rate might be detrimental. If the kinetic parameters correlate with the in vivo prop- erties (e.g. effect on the targets, blood glucose and insulin levels, pharmacokinetics) of the compounds, SPR might be useful for selecting compounds to be tested in vivo. The onrate of OSI906 for binding to phosphorylated IGF1R is about 260 lower than that of AEW541. Since these two structurally related compounds presumably interact with this protein in a similar manner, this difference might be linked to their different flexibility. The presence of a quinolinyl substituent rigidifies the OSI906 (Fig. 1). Because of its higher flexibility, AEW541 could bind to an intermediate conformation of IGF1R and the complex AEW541-enzyme could relax to reach the final conformation. The initial binding step would allow the free energy barrier between the unbound state and the final complex to be lowered, which would explain the higher on-rate of AEW541. Such a mechanism may not occur with the more rigid OSI906, which might only bind to a conformation similar to the final conformation. In this case, the free energy barrier between the free and bound state would be high explaining the lower on-rate of OSI906.

We have also observed that the on-rates measured with AEW541, TAE226 and STAURO and the phosphorylated proteins are higher than those seen with the unphosphorylated proteins. The structures of unphosphorylated IGF1R and IR $[31,32]$ reveal that the activation loop takes a conformation (hereafter called a closed conformation) such that it prevents substrate binding to the active site. In solution, it has been shown that more than $90 \%$ of unphosphorylated IR is in a closed conformation [33]. In contrast, the activation loop in the phosphorylated enzymes $[11,25]$ has moved away and takes a conformation (hereafter called an open conformation), which allows substrate binding. Since AEW541, TAE226 and STAURO bind preferentially at the ATP binding site of phosphorylated IGF1R/IR in an open or open-like conformation, their binding to unphosphorylated IGF1R/IR requires the proteins to shift from a closed to an open conformation. If this conformational change is a slow process, with a high free energy barrier, it should affect the binding of the compounds. One might thus expect the $\mathrm{k}_{\text {on }}$ values measured with the unphosphorylated enzymes to be lower than those determined with the phosphorylated enzymes in which the activation loop is preferentially in an open conformation. This is what is observed with AEW541, TAE226 and STAURO.

\section{CONCLUSION}

In summary, our work shows that the selectivity of IGF1R inhibitors measured in cells is not obtained in any of the biochemical assays (enzymatic, calorimetry and surface plasmon resonance) that we have used. This suggests that either the biochemical assays do not permit to recapitulate the true conformation of the IGF1R and/or IR proteins or that the selectivity measured in cells depends on more complex events than just the binding of these inhibitors to their target. Detailed cellular studies, similar to our biochemical studies, may help in understanding the mechanisms that create this cellular specificity. However, the biochemical assays permit to get very useful information on the properties of the inhibitors that can be exploited in drug discovery. For example, revealing that compounds have very different $k_{\text {off }}$ (here AEW541 and OSI906) might be useful for the selection of molecules that may have a very different pharmacological profile in vivo. 


\section{ACKNOWLEDGEMENTS}

We would like to thank Dr. F. Bitsch for his help in microcalorimetry and mass spectrometry analysis and Dr. J. Ottl for his help in the dynamic light scattering experiments.

\section{SUPPLEMENTARY MATERIAL}

Supplementary material is available on the publishers Web site along with the published article.

\section{REFERENCES}

[1] DeMeyts P,Whittaker J. Structural biology of insulin and IGF1 receptors: implications for drug design. Nat Rev Drug Discov 2002; 1: 769-83.

[2] Adams TE, Epa VC, Garrett TP, Ward CW. Structure and function of the type 1 insulin-like growth factor receptor. Cell Mol Life Sci 2000; 57: 1050-93.

[3] Liu JP, Baker J, Perkins AS, Robertson EJ, Efstratiadis A. Mice carrying null mutations of the genes encoding insulin-like growth factor I (Igf-1) and type 1 IGF receptor (Igf1r). Cell 1993; 75: 5972.

[4] Hartog H, Wesseling J, Boezen HM, Graaf WTA. The insulin-like growth factor 1 receptor in cancer: old focus, new future. Eur $\mathbf{J}$ Cancer 2007; 43: 1895-904.

[5] Yuen JSP, Macaulay VM. Targeting the type 1 insulin-like growth factor receptor as a treatment of cancer. Expert Opin Ther Targets 2008; 12: 589-603.

[6] Ryan PD, Goss PE. The emerging role of the insulin-like growth factor pathways as a therapeutic target in cancer. Oncologist 2008; 13: 16-24.

[7] Tao Y, Pinzi V, Bourhis J, Deutsch E. Mechanisms of disease: signaling of the insulin-like growth factor 1 receptor pathway therapeutic perspectives in cancer. Nat Clin Prat Oncol 2007; 4: 591-602.

[8] Paz K, Hadari YR. Targeted therapy of the insulin-like growth factor-1 receptor in cancer. Comb Chem High Through Screen 2008; 11: 62-9.

[9] Rodon J, DeSantos V, Ferry RJ, Kurzrock R. Early drug development of inhibitors of the insulin-like growth factor-1 receptor pathway: lessons from the first clinical trials. Mol Cancer Ther 2008; 7: 2575-88.

[10] Li R, Pourpak A, Morris SW. Inhibition of the Insulin-like Growth Factor Receptor-1 5IGF1R) tyrosine kinase as a novel therapy approach. J Med Chem 2009; 52: 4981-5004.

[11] Hubbard SR. Crystal structure of the activated insulin receptor tyrosine kinase in complex with peptide substrate and ATP analog. EMBO J 1997; 16: 5573-81.

[12] Garcia-Echeverria C, Pearson MA, Marti A, et al. In vivo antitumor activity of NVP-AEW541 - A novel, potent, and selective inhibitor of the IGF-1R kinase. Cancer Cell 2004; 5: 231-9.

[13] Ji QS, Mulvihill MJ, Rosenfeld-Franklin M, et al. A novel, potent, and selective insulin-like growth factor-1 receptor kinase inhibitor blocks insulin-like growth factor-1 receptor signaling in vitro and inhibits insulin-like growth factor-1 receptor-dependent tumor growth in vivo. Mol Cancer Ther 2007; 6: 2158-67.

[14] Blum G, Gazit A, Levitzki A. Substrate competitive inhibitors of IGF-1 receptor kinase. Biochemistry 2000; 39: 15705-12.
[15] Liu TJ, LaFortune $\mathrm{T}$, Honda $\mathrm{T}$, et al. Inhibition of both focal adhesion kinase and insulin-like growth factor-1 receptor kinase suppresses glioma proliferation in vitro and in vivo. Mol Cancer Ther 2007; 6: 1357-67.

[16] Erdmann D, Zimmermann C, Fontana P, Hau JC, De Pover A, Chène $\mathrm{P}$. Simultaneous protein expression and modification: an efficient approach for production of unphosphorylated and biotinylated receptor tyrosine kinase by triple infection in baculovirus expression system. J Biomol Tech 2010; 21(1): 9-17.

[17] Erdmann D, Allard B, Bohn J, et al. Kinetic study of human full-length wild-type JAK2 and V617F mutant proteins. Open Enzyme Inh J 2009; 1: 80-84.

[18] Morton TA, Myszka DG. Kinetic analysis of macromolecular interactions using surface plasmon resonance. Meth Enzymol 1998; 295: 268-94.

[19] Önell A, Andersson K. Kinetic determinations of molecular interactions using Biacore - minimum data requirements for efficient experimental design. J Mol Recog 2005; 18: 307-17.

[20] Baer K, Al-Hasani H, Parvaresch S, et al. Dimerization-induced activation of soluble insulin/IGF-1 receptor tyrosine kinases: an alternative mechanism of activation. Biochemistry 2001; 2001: 14268-78.

[21] Ablooglu A, Kohanski RA. Activation of the insulin receptor's kinase domain changes the rate-determining step of substrate phosphorylation. Biochemistry 2001; 40: 504-13.

[22] Walker DH, Kuppuswamy D, Visvanathan A, Pike LJ. Substrate specificity and kinetic mechanism of human placental insulin receptor/kinase. Biochemistry 1987; 26: 1428-33.

[23] Segel IH. Enzyme kinetics. Behavior and analysis of rapid equilibrium and steady-state enzyme systems, New York, John Wiley \& Sons, Inc., 1975.

[24] Shoichet BK. Screening in a spirit haunted world. Drug Discov Today 2006; 11: 607-15.

[25] Favelyukis S, Till JH, Hubbard SR, Miller WT. Structure and autoregulation of the insulin-like growth factor 1 receptor kinase. Nat Struct Biol 2001; 8: 1058-63.

[26] Gruppuso PA, Boylan JM, Levine BA, Ellis L. Insulin receptor tyrosine kinase domain auto-dephosphorylation. Biochim Biophys Res Comm 1992; 189: 1457-63.

[27] Karlsson R, katsamba PS, Nordin H, Pol E, Myszka DG. Analyzing a kinetic titration series using affinity biosensors. Anal Biochem 2006; 349: 136-47.

[28] Li W, Favelyukis S, Yang J, et al. Inhibition of insulin-like growth factor I receptor autophosphorylation by 6-5 ring-fused compounds. Biochem Pharmacol 2004; 68: 145-54.

[29] Wu J, Li W, Craddock BP, Foreman KW, Mulvihill MJ, et al. Small-molecule inhibition and activation-loop trans-phosphorylation of the IGF1 receptor. EMBO J 2008; 27: 1985-94.

[30] Tummino PJ, Copeland RA. Residence time of receptor\#ligand complexes and its effect on biological function. Biochemistry 2008; 47: 5481-92.

[31] Hubbard SR, Wei L, Ellis L, Hendrickson WA. Crystal structure of the tyrosine kinase domain of the human insulin receptor. Nature 1994; 372: 746-54.

[32] Munshi S, Kornienko M, Hall DL, et al. Crystal structure of the apo, unactivated Insulin-like Growth factor-1 receptor kinase. J Biol Chem 2002; 277: 38797-802.

[33] Frankel M, Bishop S M, Ablooglu A J, Han Y P, Kohanski R A. Conformational changes in the activation loop of the insulin receptor's kinase domain. Prot Sci 1999; 8: 2158-65. 